\title{
COLLABORATIVE LEARNING IN THE 21ST CENTURY TEACHING AND LEARNING LANDSCAPE: EFFECTS TO STUDENTS' COGNITIVE, AFFECTIVE AND PSYCHOMOTOR DIMENSIONS
}

\author{
Romeo Jr. B. Sotto ${ }^{*}$ \\ 'Camarines Sur Polytechnic Colleges, Instructor, Nabua, Philippines \\ *sottoromeojr@gmail.com
}

\begin{tabular}{l}
\hline Article Info \\
\hline Article history \\
Received; December 30, 2020 \\
Revised: January 25, 2021 \\
Accepted: February 9, 2021 \\
\hline
\end{tabular}

Keywords: Affective; Cognitive; Collaborative learning;

Psychomotor

\begin{abstract}
Collaborative Learning $(\mathrm{CL})$ is an approach to teaching and learning that involves a group of learners working together. The study aims to assess collaborative learning effects in the

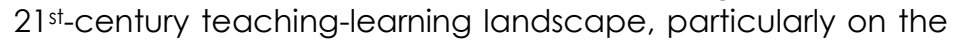
students' cognitive, affective and psychomotor dimensions. This study utilized the descriptive-evaluative method of research with a validated questionnaire as the primary data gathering instrument. Results showed that females dominate male students as to their number in first and second-year levels. The majority of the respondents aged 20 and below have participated in various collaborative activities and assignments in and out of the class with a typical size of 5 to 7 group members. Collaborative learning was found to have a very high effect on Students' Academic Learning (cognitive), Collaborative Skills (affective) and least on Skills development (psychomotor). The researchers recommend that male students be engaged in group dynamics and learning activities; it must involve teenagers and suffice their activities' preference. Activities that demand greater participation, drills and exercises, and thinking activities must allow the students to develop their cognitive, affective, and psychomotor dimensions for holistic learning.
\end{abstract}

\section{INTRODUCTION}

Collaborative learning includes a wide range of approaches that differ concerning the amount of in-class and out-of-class time devoted to group work. The activities can involve face-to-face conversations and/or computers to conduct discussions (online forums, social media networks, etc.). Irrespective of the teaching approach adopted, collaboration among learners and/or between learners and the teacher constitutes an integral element in language learning. PBL (problem-based learning), project work and task-based learning are examples of collaborative learning. Numerous studies on collaborative learning have focused on evoking positive interdependence in higher education institutions (Escager et al., 2016); teacher and student perceived obstacles to effective student collaboration (Le et al., 2017); educational achievement (Chandra, 2015) or on Effects of group experience and information distribution on collaborative learning (Zambrano et al., 2019). Less attention gave to the effects of collaborative learning on students' cognitive, affective and psychomotor 
dimensions. Thus, this article highlights the extent to how collaborative learning affects the students' cognitive dimension (i.e. the knowledge assimilation among students through active interaction), affective dimension (i.e. how the students develop values and good attitudes through collaboration among peers), and psychomotor dimension (i.e. the students' ability to develop new skills and enhance learned skills through activities and group dynamics).

Collaborative learning has increasingly become important in schools and organizations. It is the process by which learners interact in small groups to learn (Slavin, 2014). Students' achievement and productivity rely on their immediate environment and their relationship with the people around them, especially their classmates. According to Thornburg (2000), the cusp of an altogether "new era" and changes must be made in education to ensure that all students leave school prepared to face the challenges of a redefined world.

Cooperative learning widely is recognized as a pedagogical practice that promotes socialization and learning among students from pre-school to tertiary and across different subject domains. It involves students working together to achieve common goals or complete group tasks - goals and tasks they would not complete by themselves (Gillies, 2016). Learning plays a necessary part in improving oneself. It is one of the essential mental functions of humans, animals, and artificial cognitive systems. It relies on acquiring different types of knowledge supported by perceived information, leading to developing new capacities, skills, values, understanding, and preferences leading to higher productivity implications. Its goal is to increase individual and group experiences within a given environment. Learning functions can be performed by different brain learning processes, which depend on the mental capacities of learning subjects and achieving goals, which has to be justified and socio-cognitive and environmental circumstances.

Learning is a process in which students interact with their immediate environment, including their peers, classmates and teachers. Learners build knowledge as they explore the world around them, observe and interact with phenomena, converse and engage with others, and make connections between new ideas and prior understandings; it builds on prior knowledge and involves enriching, building on, and changing existing understanding, where "one's knowledge base is a scaffold that supports the construction of all future learning" (Alexander, 1996, p. 89), occurs in a complex social environment and thus should not be limited to being examined or perceived as something that happens on an individual level.

Instead, it is necessary to think of learning as a social activity involving people, the things they use, the words they speak, the cultural context they are in, and the actions they take (Bransford et al., 2006; Rogoff, 1998), and that knowledge built by members in the activity (Scardamalia \& Bereiter, 2006), is situated in an authentic context provides learners with the opportunity to engage with specific ideas and concepts on a need-to-know or want-to-know basis (Greeno, 2006; Kolodner, 2006). Lastly, it requires learners' motivation and 
cognitive engagement to sustain when learning complex ideas because considerable mental effort and persistence are necessary.

The conditions for inputs to learning are clear, but the process is incomplete without making sense of what outputs constitute learning has taken place. At the core, learning is a process that results in a change in knowledge or behaviour as a result of experience. Understbehaviourhat takes to get that knowledge in and out (or promote the behavioural change of a specific kind) can behaviourally learn. Collaborative learning is a positive, inclusive and powerful learning strategy that engages students throughout their school life and has had a significant positive impact on classes' personal outcomes.

Collaborative Learning $(\mathrm{CL})$ is an educational approach to teaching and learning that involves groups of learners working together to solve a problem, complete a task, or create a product. It also refers to an instruction method in which learners at various performance levels work together in small groups toward a common goal. Moreover, now we emphasize the impact of elaborative emphasis on a student's academic performance. It is about the teacher's patience and effort to facilitate the students' teaching-learning through collaborative learning. Furthermore, this research undertaking will serve as an appraisal of the impact of collaborative learning on students' academic performance.

Teacher education students are highly bombarded with expectations of achieving high and producing more. Thus, instructors utilized various methods to enable them to develop holistically. The students' productivity and achievement strongly rely on their adaptive measures to drastic changes from senior high school to college.

In this research, the respondents were the 1st year and 2nd year teacher education students. The effects of collaborative learning on the cognitive, affective and psychomotor dimensions of the 1st year and 2nd year teacher education students are the main foci of this research undertaking. As one of the College of Teacher Education instructors, the researcher felt the need to know the effects of collaborative learning on the students' cognitive, affective and psychomotor dimensions. It premised on the assumption that collaborative learning heightens these dimensions of the students. This research undertaking aims to know the effects of collaborative learning on students' cognitive, affective and psychomotor dimensions of 1st year and 2nd-year teacher education students. Specifically, it aims to answer the following questions: 1) What is the profile of the respondents in terms of age and sex?; 2) What are the effects of Collaborative learning along (a) Academic Learning (Cognitive), (b) Collaborative Skills (Affective); and, (c) Physical Development (Psychomotor)? And; 3. What intervention guide/manual can develop to achieve collaborative learning in classrooms?

The need to determine the effects of collaborative learning on the students' cognitive, affective and psychomotor dimensions was the study's subject. This study aims to give factual determinant of the effects of collaborative learning. This study's conduct was rooted in three 
foundation theories of education: Bioecological Theory by Urie Bronfenbrenner, Cone of Experience by Edgar Dale and Socio-cultural Theory by Lev Vygotsky. The researcher's theory titled Socio-ecological Development Theory indicates that there is an excellent system to wit. The students or learners can gain optimum learning through attention, valued experience, and varied application, thus increasing cognitive, affective and psychomotor dimensions.

Bioecological Theory by Urie Bronfenbrenner states that learning has different systems: the mesosystem, macrosystem and the exosystems. These systems surround the learner/individual that significantly surrounds direct effect on the learning of the learner. With this theory, the researcher derived the idea that the learner needs to interact with his/her environment, precisely the purpose of collaboration, to help develop the child through active participation.

Cone of Experience by Edgar Dale is a graphical representation of how the learner's learning capacity and increasing productive learning capacity. According to the cone, as the students/learners continuously go up the cone, the more abstract the lesson. As the learner is directly involved in the learning process, the more the student will learn. Edgar Dale's cone of the experience gave the researcher the idea that experiences inside the classroom must start from the most concrete to abstract in collaboration and interaction with his/her peers to attain optimal learning experience.

Socio-cultural Theory by Lev Vygotsky states that external factors influence learners. External factors influence learners. More Knowledgeable Others (MKO) will follow the Zone of Proximal Development and Scaffolding. According to this theory, learners learn through the guidance of experts in the field or those termed as More Knowledgeable Others. Once the learner thoroughly guided, the learner is said to be in the Zone of Proximal Development where there is less guidance from others to pave the way for more significant development of the learner and lastly is the scaffolding where the learner guided by less instruction and expected to make it by his/her self. The theory by Lev Vygotsky intends to elucidate the value of application through the help of others. The way of helping is one way of interacting. It correlates to the study because cooperative learning aims to give learners the optimal learning experience through interaction with others.

\section{REVIEW OF RELATED LITERATURE AND STUDIES}

Self-directed work teams saw an essential mechanism for dealing with today's complex and rapidly changing business environment. Team learning is an attempt to prepare students for real-world experiences. Nevertheless, not all teamwork is effective. It papeHoweverims to examine the influence of learning style preferences on team learning performance. The Grasha-Riechmann Student Learning Style Scales (GRSLSS) used to assess the business's learning style preferences. Business students enrolled in an operation student found to be collaborative learners. Students' collaborative orientation complements participation and 
helps students to compete, which in turn increases team performance. Also, the influence of learning style varies with educational experience, gender and major. Graduate students showed to be collaborative and independent learners. As such, while personal and formal authority teaching styles fit best undergraduates' learning preferences, the instructor's role changes to facilitator and delegator at the graduate level. Provides evidence that learning style preferences are valuable for engaging learners in various collaborative activities and designing successful diverse teams.

Collaboration is the new buzzword in education. It is often sawed as the panacea for all of education's ills. Some schools fail to take the time to investigate the concept in more depth because they feel they already do that. Schools point to standard practices that occur all the time in schools as evidence of collaboration taking place in their buildings. Conversations at team or department meetings, dialogues between teachers in the lounge, informal talks in the hallways between classes, and conferences between administrators and teachers are all used as examples of collaborative practices. However, authentic collaboration goes much deeper. To reap the benefits of true collaboration, schools must investigate the approach indepth and understand what distinguishes collaboration from all other interactions.

Collaboration is a systematic process in which educators work together to analyze and impact professional practice to improve individual and collective results. Administrative support for collaboration is essential for its success. Principals must provide time during the workday for collaborative teams to meet and require teams to concentrate their efforts on specific achievement goals. For collaboration to be successful, it cannot be sporadic. It cannot happen occasionally. It cannot be random, and it cannot meander from topic to topic without structure.

When adults meet in collaborative grade level or curriculum groups, there should be an agenda for each meeting. When someone asks, "What are we supposed to be doing today?" it is likely that the group will not be very productive. Teams can also spend time rehashing the same topics and conclude that "meetings are a waste of time." By establishing agendas before each meeting and making each group member aware of the plan and the responsibility to remain focused on the topic under discussion, the meetings will flow more smoothly. The conversations will be productive, and the adults will realize that they are their powerful resources. In short, they are participating in job-embedded staff development, a practice that can lead to student success.

An examination of the topic of collaboration begs the question: What can adults expect from their collaborative efforts? In short, will all of our efforts pay off? In her research, Judith Warren Little writes about the advantages of working together in collaborative teams. She found that when true collaboration occurs, adults can expect gains in student achievement, unforeseen solutions to problems, a reduction in teacher isolation, increased 
confidence among staff members, a desire to test new ideas, more support for new teachers, and an expanded repertoire of strategies, materials, and teaching approaches.

Collaborative teams often begin with the best of intentions. They agree to concentrate their conversations on practices that will enhance student learning. However, over time, reality sets. The initial excitement wanes as teachers become tired, overburdened, mired in paperwork, or distracted by unforeseen events. They want to retain their commitment to student learning but may need additional inspiration to spur them to meet their collective goals. Listed below are a series of topics/questions that will help curriculum or grade level teams regain their focus and eventually maintain the momentum they established when they began working together. The topics or questions will potentially lead to lively discussions, effective sharing, increased adult learning, and ultimately improve student achievement.

Collaborative learning activities vary widely, but most centre on the learner's exploration or application of the curriculum, not simply on the teacher's presentation of it. Students make individual progress in tandem with others, working towards a common goal. Students are accountable to one another and, with appropriate direction, will self-manage this. Pupils learn to understand better and anticipate difference, recognize it in themselves and others, and use it to their advantage.

The beauty of a collaborative approach is that it offers such flexibility, so grouping students in an optimum way and refine and adapt groups as they travel along the journey. Collaboration provides a full range of models adapted to suit whole-class, multi-team and small-team settings as a learning experience.

Most importantly, a practical collaborative approach does not lose sight of the individual. The uniqueness of each student is and how important it is to tailor their distinctive learning styles. Collaboration, done right, plays to this perfectly. There is still room for personalized instruction and guidance to ensure that all attitudes and abilities are accommodated.

A collaborative approach does not assume that everyone will travel at the same speed. The brighter children will not hold back, as they will incline to guide the outliers. Furthermore, the outliers will benefit from a more robust network of group support and direction.

Nowadays, blended learning can relate to any combination of different ways of learning, different learning styles and various learning environments. In brief, the operative application of blended learning is primarily about creating chances for learning opportunities and instruments to achieve the optimal learning environment (Marsh, 2012). 3.3.1 Collaborative Concept The idea of collaborative learning dates back to between 1950 and 1960 to that used by doctors to deal and communicate with medical students, where it noted that the students who were working in groups had a medical assessment and results better than those who were working alone which reflected the great success of this idea. The

IJEMI Vol.2, No.2, May 2021, pp. 136 152 
best way to understand the method of collaborative learning is with the definition of these concepts as viewed by Swan et al. (2006, p. 46):

Collaborative learning is a teaching strategy that includes a small group of learners working together to develop the educational experience to the maximum extent possible. Collaborative learning defined as the work of individuals as members of groups. Each student of the group is linked to mental, emotional, and behavioural functions to achieve the community and systems' objectives whose clear objectives help learners in the decisionmaking process and increase community sense. Concept Long-term Environment Openended Results-oriented

Collaborative learning stands on the idea that learning is a naturally social act in which learners talk amongst them. Among the talk, learning occurs. Collaborative learning is "a case, where such a case includes the following main aspects: first, two or more students learn or try to learn something together; second, 'two or more may be explained as a pair, a small group (3-5 subjects) or a class (20-30 subjects); third, 'learn something' may be explained as following a course or perform learning activities such as problem-solving. Finally, 'together' may be explained as many forms of interaction which may be face-to-face or computermediated". Arguably collaborative learning aims to support the most effective teaching possible for the most significant number of students. Laal and Laal (2012, p. 492-493) pointed out that there are five essential elements in the problem-solving learning environment:

Collaborative learning perceives positive correlation; members in the workgroup commit to depend on one another to achieve the goal. Furthermore, if any member fails to perform their task or responsibility, all group members suffer the consequences. The teacher must plant in the learners' hearts the importance of collaborative teaching to build a collaborative learning environment. Excellent communication and interaction: developing practical communication skills to interact with others contributes to exchanging information and ideas through various channels to achieve the goals. Furthermore, successful communication depends on several factors, such as the interaction between the teacher and the learner and the means of delivery and the effects of the surrounding environment.

Individual accountability and personal responsibility; each student in the team is responsible for performing their task and reaching a high mastery level. Social skills: understanding the behaviour of each student is imperative to succeed. There are many social skills learners should have, such as confidence, calm, decision making, empathy, smiles, and communication. Group self-evaluating: to improve the teaching and learning process and development, this should focus on the importance of a teacher competency 50 standard in the educational process and student assessment such as philosophy of education goals, defining curriculum content and textbooks under consideration, identifying objectives and analyzing their content, and knowledge of their learning styles. 
On the other hand, many previous studies and literature confirm the significance of students' effective participation and collaboration in supporting their effectiveness. The evaluation of collaboration needs a radical rethinking of approaches and methodologies. In this context, Swan et al. (2006, p. 46-47) pointed to three main issues which are involved in the assessment process: The variety and kinds of goals for collaborative learning: these include distinguishing between the teacher who built the learning goals for his students on a collaborative basis, and between the teacher who made it on a competitive basis or individually. Besides, collaborative learning should distinguish between students who work in the form of learning groups or conventionally and among the students who work in cooperative learning groups.

Furthermore, collaborative learning should distinguish between the essential elements of cooperative learning implemented in the cooperative learning elements to investigate the learning plan implementation's efficiency prepared with the cooperative learning method. The study also addresses the effect of cooperative learning on students' achievement and their views regarding the 'Systems in Our Body' unit of the 6th grade Science and Technology lesson. For this purpose, a mixed-method is used. The studies conducted in the second term of the 2013-2014 academic year on a study group consisted of 7 girls and 13 boys, 20 students of a private middle school in Istanbul. An achievement scale utilized for the quantitative data, and focus group interviews held for the qualitative data. While the t-test was used for the quantitative findings, the content analysis technique was used for the qualitative data. The result of the study indicated that the $\mathrm{CL}$ method had a favourable effect on learning. The cooperation-based learning-teaching environment provided cooperation, supported permanent learning, provided opportunities to be successful, contributed to social and personal skills, and caused worry. It requires students to be successful at all stages.

Cooperative learning is an excellent logical practice that promotes socialization and learning among students from preschool to tertiary and across different subject domains. It involves students working together to achieve common goals or complete ground - goals and tasks that they would be unable to complete by themselves. This paper aims to review developments in research and practice on cooperative learning and examine the factors that explain its success. The review focuses on the key elements contributing to its success and the role teachers play in developing students' thinking and learning when implementing.

The pedagogical practice aims. Collaborative learning is an approach employed by instructors to facilitate learning and improve learner's performance. Mobile learning can accommodate a variety of learning approaches. Therefore, this study investigated the effects of collaborative learning styles on students' performance in mobile learning. The poses of this study are to: examine the difference in the performance of students in mobile learning platform; examine the difference in the performance of students in the five collaborative learning styles; examine the significant difference in performance between collaborative and

IJEMI Vol.2, No.2, May 2021, pp. 136 152 
non-collaborative learning styles; and determine the effect of collaborative learning style on student's performance in a mobile learning platform - the purposive sampling technique used to choose 36 secondary school students as the sample. The study adopted a pretest-posttest experimental approach and was randomly assigned to the five collaborative and one noncollaborative learning groups-the groups exposed to mobile learning on the mole concept (MLMC) in Chemistry. The results showed significant gains regarding the difference between pretest and posttest scores of students in the mobile learning experience. The think-aloud-pair problem-solving technique is the most effective collaborative learning style-all the col. The active learning styles are more effective for learning in a mobile learning environment than non-collaborative learning styles.

Collaboration is a way of interaction and personal attitude where individuals are responsible for their actions, learning, abilities, and contributions. This paper clarifies the concept of collaborative learning by presenting and analyzing the educational benefits of Collaborative learning techniques. Collaborative learning is more students centred. The collaborative tradition takes a more qualitative approach, analyzing student talk in response to a piece of literature. This paper clarifies the differences between collaborative and individual learning. The article also highlights the teacher's perspective on individual and collaborative learning. The paper concludes with a discussion about these issues concerning undergraduate students' achievement in English. The T-test used to sin achievement in English by using collaborative learning and individual learning. The sample comprises 40 students (males 30 , females 10) of the undergraduate program. Purposive sampling has used. The final achievement scores in English have been used for the study.

\section{RESEARCH METHOD}

This research used the Descriptive-Evaluative Survey Method with a validated questionnaire as the primary data gathering instrument. According to Fiscal (2010), Descriptive research designs are considered more structured than the experimental research design. This design also helps find the answers to the questions associated with the specific research study. Through this, the data collected is measurable to produce a description of the variables.

According to Naval, Carey and Prieto, descriptive research gathers information on current situations and conditions. It helps answer the questions of who, what, when, where, and how of a particular research study. Descriptive research studies provide accurate data after subjecting them to a rigorous procedure and using a large amount of data from a large number of samples. This design leads to logical conclusions and pertinent recommendations. Specifically, the survey research design used to secure opinions and trends through questionnaires and interviews. 
Ethics considered into account to preserve and protect the anonymity of the respondents of the study. The study respondents were the first year and second-year students of the College of Teacher Education year 2019-2020 selected as the respondents. They were the first two batches to graduate in the new education shift of the Philippines. The $\mathrm{K}$ to 12 graduates called the 21 st-century learners, and with that premise, this study focused on them. The respondents took from the total population of the two-year levels, 117-the sample size of 95 respondents using the Slovin's Formula.

In gathering the data needed for this study, the researchers used several methods that contributed much to the findings' substantial presentation. This study employed a self-made questionnaire, referred materials, observation and interview. It was made from the problem statement to make sure that the necessary data from the respondents obtained. The process of descriptive research goes beyond the gathering of tabulation of data. It involves an element of interpretation of the meaning or significance of what described. In this study, the method is beneficial since it draws out the whole picture on the effects of Collaborative learning of students' cognitive, affective and psychomotor dimensions.

Therefore, descriptive research is deemed to be the most suited method utilized in this study. It bears an in-depth analysis of the status quo and gives an accurate interpretation of this study's output.

\section{RESULTS AND DISCUSSION}

Data gathered was statistically analyzed, interpreted and discussed pertinent to Collaborative Learning's implications to the academic student's performance problem statement year. The respondents' necessary data to provide a clear and vivid presentation.

\subsection{Personal Profile of the Respondents}

Based on the problem statement, the researchers wanted to know the respondents' profile to benchmark if the respondents' beneficiation is teenagers and male students.

\subsubsection{Age.}

Age is a determining factor of a person's ability. It indicates the maturity and development of an individual and dictates his/her ability to learn things from his/her environment. This study aims to assess the respondents' age, sex, and year level to determine the respondents' prominent age groups and the number of respondents for both gender and year level. Figure 1 shows the respondents distribution. 


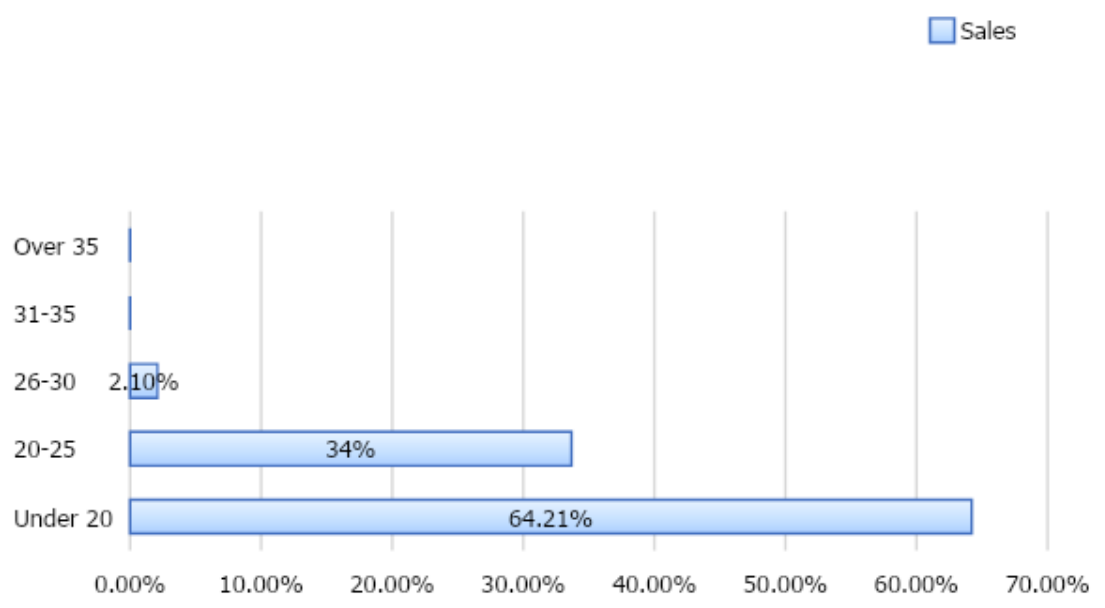

Figure 1. Respondents' Age Distribution

Shown in figure 1 is the age of the respondents of this study. It consists of 95 students from 1st year and 2nd-year teacher education students. Out of 95 respondents, 61 (64.21\%) teacher education students were under 20 years old, 32 (33. 68\%) teacher education students were 20-25 years old, 2 (2.10\%) teacher education students were 26-30 years old, and no respondents were 31-35 and over 35 years old. This data implies that the majority of the respondents are teenagers. Being in their teenage years, being proactive and involved in groups are the most notable features. According to the study made by Backer et al., students in this age group are unique. They need attention that is more of an adult and less of a child, and collaborative learning allows them to develop their productivity and achieve more.

\subsubsection{Sex.}

Sex is the biological classification of an individual in which workloads can be predetermined and modified later in life. In this study, sex determined to know the jobs/tasks that may design in a group. Shown in figure 2 is the sex of the respondents of this study.

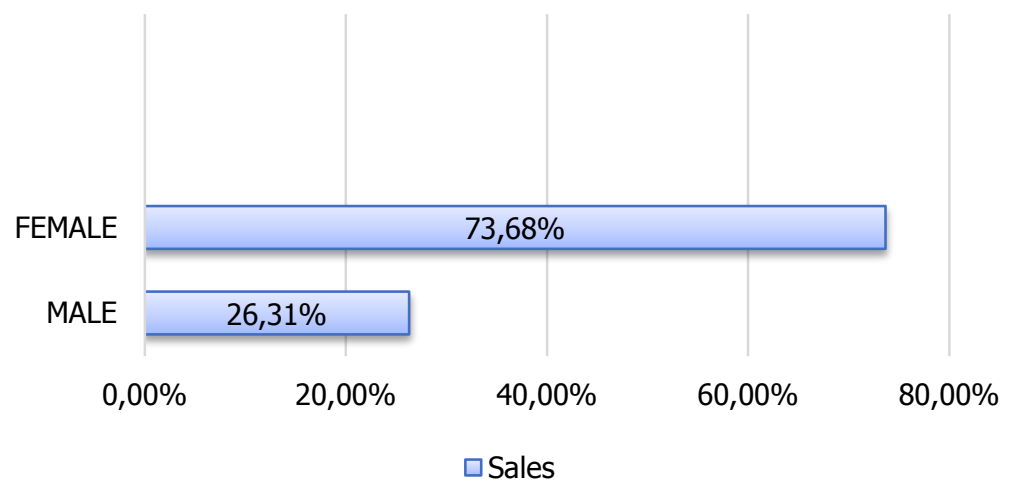

Figure 2. Respondents' Sex Distribution 
Figure 2 shows that the respondents were composed of 95 students from $1^{\text {st }}$ year and

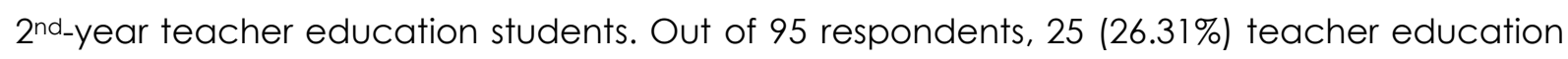
students were male, and 70 (73.68\%) teacher education students were female. It implied by the data above that majority of the respondents were females. Based on the data, it can be inferred that stereotypes and discrimination are not anymore present in a $21^{\text {st-century }}$ classroom.

\subsection{Effect of Collaborative Learning on Students' Cognitive, Affective, and Psychomotor Dimensions}

Collaborative learning is an educational approach to teaching and learning. It aims to tap several dimensions of the students to provide holistic learning to students. Collaborative learning focuses primarily on how the students acquire knowledge and the values and interactions that the students experience while learning. These dimensions are the cognitive, affective and psychomotor dimensions.

\subsubsection{Academic Learning (Cognitive).}

Collaborative learning enables students to develop and acquire knowledge through others and themselves. It allows students to understand the concepts and lessons through a constructivist perspective. Students can view things from their classmates' point of view, thus, enabling them to see a more comprehensive picture. Figure 3 shows the effect of collaborative learning on students' cognitive dimension.

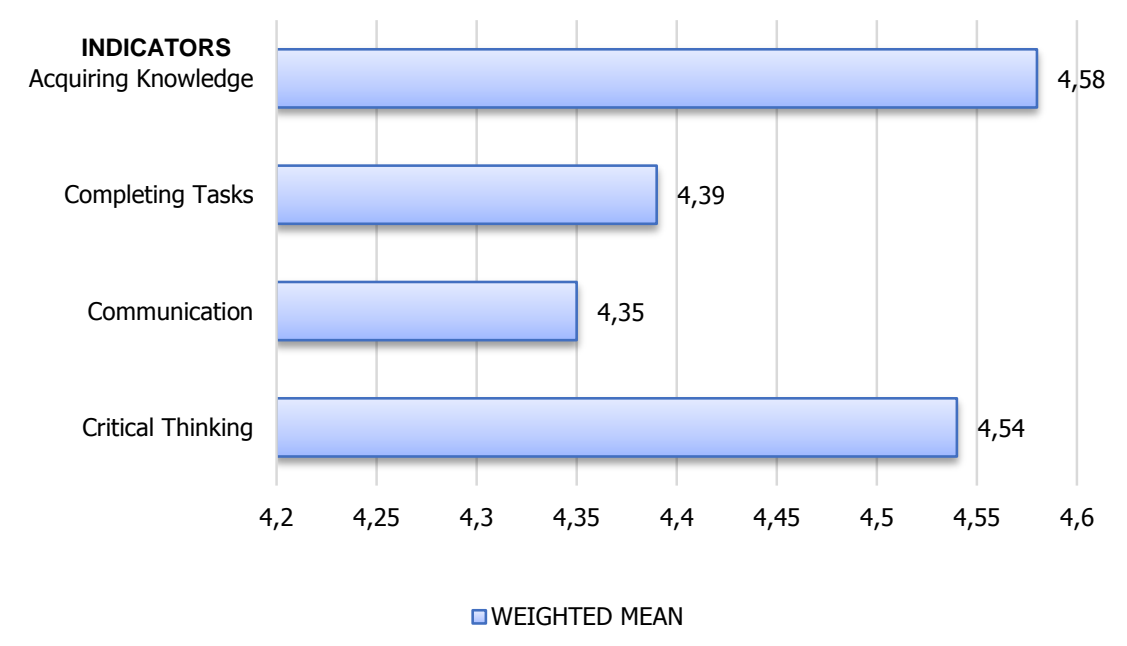

Figure 3. Effects on Cognitive Dimension

The effect of collaborative learning on students' cognitive dimension among the different indicators, Acquiring knowledge has the highest weighted mean of 4.58. Critical thinking has a weighted mean of 4.58. Completing tasks have a weighted mean of 4.39 , and communication has a weighted mean of 4.35 , all interpreted as Very High Effect. As rated by 
the respondents, collaborative learning has a very high effect on knowledge acquisition and least on communication. The data imply that collaborative learning poses effective transmission of knowledge to students.

According to the study by Van Boxtel, Van der Linden, and Kanselaar (2000), collaborative learning activities help learners to find explanations of their understanding that assists them elaborate and reorganize their knowledge. Based on the data, Academic Learning has an average weighted mean of 4.47, interpreted as Very High Effect. It means that collaborative learning found a significant effect on the students' academic learning in their activities.

\subsubsection{Collaborative Skills (Affective).}

Collaborative learning provides an avenue for students to develop their collaborative skills, fostering positive values in a team or group needed for work and real-life applications. As operational defined in this study, collaborative skills of the interpersonal or social skills that the students possess innately. Figure 4 shows the effect of collaborative learning on students' affective dimension.

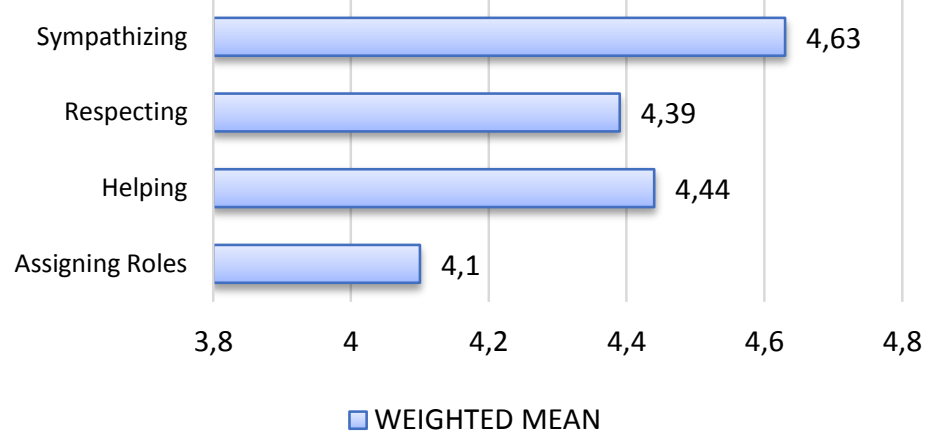

Figure 4. Effects on Affective Dimension

The effect of collaborative learning on students' affective dimension rated by the respondents among the different indicators, collaborative learning found to impact Sympathizing has the highest weighted mean of 4.63 , helping have a weighted mean of 4.44 . Respecting has a weighted mean of 4.39 , and Assigning Roles have the least weighted mean of 4.10, all interpreted as Very High Effect. Based on the data, it implied that collaborative learning enhances student's sympathy, among others. Values are more important than skills and knowledge because the latter can learn. According to the study conducted by Kyndt et al. (2013), Collaborative learning activities are beneficial in that this help enhances student achievement and persistence, change attitude and self-concept, and support those students who feel fearful while participating in classroom activities. Based on the data, Collaborative skills has an average weighted mean of 4.39 , interpreted as Very High Effect. It means that collaborative learning significantly affects the students' collaborative skills (socializing skills) in their activities. 


\subsubsection{Skills Development (Psychomotor).}

Through interactions with their peers, students learn to discover skills that strengthen their social interactions. Figure 5 shows the effect of collaborative learning on the skills of the respondents.

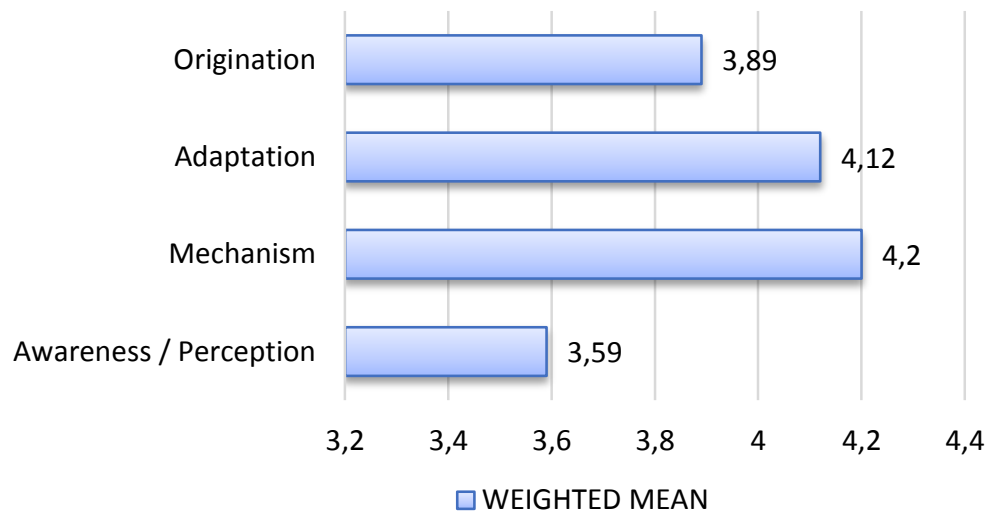

Figure 5. Effects on Psychomotor Dimension

Among the different indicators collaborative learning was found to affect - Mechanism or the development of movements that can perform with confidence and proficiency have the highest weighted mean of 4.20 interpreted as Very High Effect; Adaptation have a weighted mean of 4.12 interpreted as High Effect; Origination has a weighted mean of 3.89 interpreted as High Effect, and least likely on Awareness/ Perception have a weighted mean of 3.59 interpreted as High Effect. It implied that collaborative learning effects mostly on Mechanism. Students can eventually put into practice or habits the skills they saw in others and even copy and improve other people's actions around them. Based on the data, Skills Development has an average weighted mean of 3.95, interpreted as High Effect. It means that collaborative learning found a significant effect on the students' skills development in their activities. Figure 6 shows a summary of the three dimensions as to the impact of Collaborative learning.

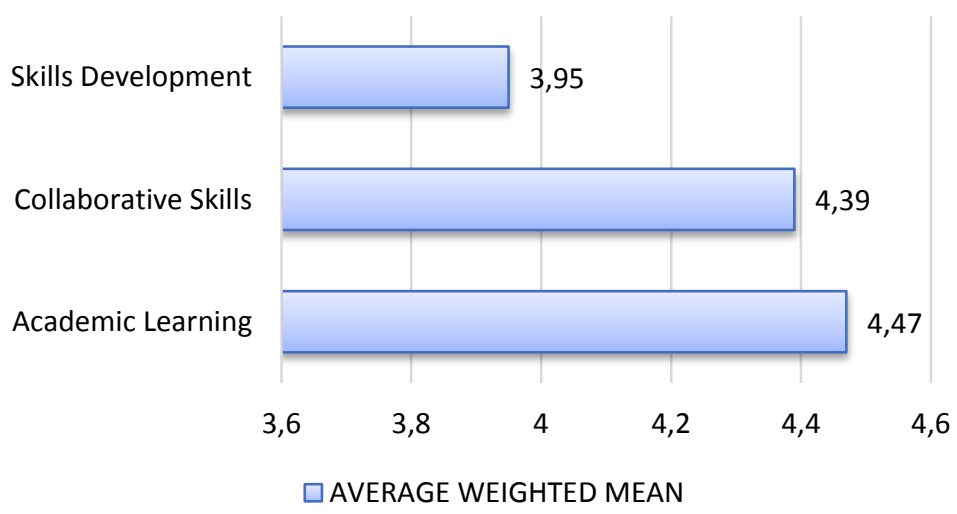

Figure 6. Summary of Average Weighted Mean for each Dimension 
Among the three dimensions of learning, Academic Learning has the highest average weighted mean of 4.47, interpreted as Very High Effect, followed by Collaborative Skills, which have an average weighted mean of 4.39 , interpreted as Very High Effect and Skills development, which have an average weighted mean of 3.95 interpreted as High Effect. It implied that Collaborative Learning affects the students' cognitive dimension and least on the psychomotor dimension. Collaborative learning is indeed a valuable tool for delivering the lessons but not developing the students' skills.

\section{CONCLUSION}

In the light of the findings, the following conclusions were drawn: (a) Female outnumbered male students in terms of the population enrolled in the programs, and the majority are teenagers; (b) Collaborative learning significantly affects students cognitive dimension / Academic learning, indicating that it is a right teaching approach indicating that it caters the holistic learning of the students; and, A collaborative learning teaching guide developed which presents different techniques of instructions delivery and assessment methods with the use of Collaborative learning.

The researcher recommends that male students are engaged in group activities, and learning activities must involve teenagers and must suffice their preference for activities. To fully maximize Collaborative learning, activities that involve greater participation, drills and exercises and thinking activities must provide the students with the necessary cognitive, affective, and psychomotor dimensions for holistic learning. A collaborative learning teaching guide developed, which presents different instruction delivery techniques and assessment methods with the use of Collaborative learning, must be adopted by instructors in the college to provide well-rounded experiences for the students.

\section{ACKNOWLEDGMENTS}

Immeasurable appreciation and most profound gratitude for the help and support extended to the following persons who, in one way or another, have contributed to the completion of this study.

DR. ARLENE O. MONSALVE, Dean of the College of Teacher Education, for her moral support and encouragement to finish this research.

DR. MARILOU D. TINO, Director of the University Research Center, for her encouragement, intelligence suggestion, moral support and valuable insights in making this research an achievement;

The SUPER SCIENCE MAJORS and especially to DR. RAY B. ORTEGA and MR. RAMON H. CORTEZ, for unselfishly sharing their time and effort during the conduct of the study.

The CLASSMATES and FRIENDS, especially MR. FLORENCIO P. ARRABE VI for moral support throughout the completion of this research. 
The BELOVED PARENTS - ROMEO LL. SOTTO AND MARIBEL B. SOTTO AND SISTER MARIE ROSE B. SOTTO have shown their support, motivation, giving their financial support, and for love, they have extended to the researcher.

The UNIVERSITY OF SAINT ANTHONY, IRIGA CITY, provides the author with the opportunity to undergo the thesis study and for the services and facilities extended during the research study.

To GOD ALMIGHTY, for without His grace and blessings, this study will not be possible.

\section{REFERENCES}

Ahmadi, M.H., (2000), The Impact of Cooperative Learning in Teaching Mathematics

Alexander, (1996), Study of collaborative learning style and team learning performance, p. 89

Altares, P. S., et al., Elementary Statistics: A Modern Approach (Quezon City: Rex Bookstore Inc.), page 101.

Bailin, S., Case, R., Coombs, J. R., \& Daniels, L. B. (1999). Conceptualizing critical thinking.

Bandiera, M., Bruno, C. (2006), Active/cooperative learning in schools

Bossert, S. T. (1988). Cooperative activities in the classroom.

Broto, Antonio S., Statistics made Simple (2nd edition), page 179

Carey, T. G., Naval, V. C., and Prieto, N. G., (2016), Practical Research II for Senior High School

(Quezon City: Lorimar Publishing Inc.)

Chandra, R. (2015), Collaborative Learning for Educational Achievement

Dewey, (1938), Piaget, (1964), Vygotsky, (1986) Collaboration: An Essential Key to Student Achievement

Dillenbourg (Ed.), Collaborative-learning: Cognitive and Computational Approaches

Dillenbourg, P. (1999). What do you mean by 'collaborative learning?

Dillenbourg, P., Baker, M., Blaye, A., \& O'Malley, C. (1996). The evolution of research on collaborative learning.

Fiscal, R.R. (2010), Research Methods in Education: Integrating Diversity with Quantitative and Qualitative Approaches. Society Publishing. 2010 Winston Park Drive, 2nd floor, Oakville Canada

Gillies, R. M. (2016). Cooperative Learning: Review of Research and Practice. Australian Journal of Teacher Education, 41 (3). http://dx.doi.org/10.14221/ajte.2016v41n3.3

Herold, M., Landherr M.; Huber (2006), A fractal approach to implementing cooperative learning in German classrooms

Le, H., Janssen, J. \& Wubbels, T., (2017) Collaborative learning practices: teacher and student perceived obstacles to effective student collaboration, Pages 103-122

Meixia, D. et al. (2007), Teacher Interventions in Cooperative-Learning Mathematics Classes Mentz and Van Der Walt (2008), The effect of incorporating cooperative learning principles in pair programming for student teachers

IJEMI Vol.2, No.2, May 2021, pp. 136 152 
Perihan Dinc, A. (2009), Experimental evaluation of the effects of cooperative learning on kindergarten children's mathematics ability

Scager, K., Boonstra, J., Peeters, T., Vulperhorst, J., and Wiegant, F., (2016), Collaborative Learning in Higher Education: Evoking Positive Interdependence

Sherman, S., Camilli, G. (2002), Effects of Leader and Teacher Behavior on Implementation of Cooperative Learning in the Elementary School

Slavin, R. E. (2014). Cooperative learning and academic achievement: Why do groupwork work? Anales de Psicología/Annals of Psychology, 30, 785-791. https://doi.org/10.6018/analesps.30.3.201201.

Thornburg, D. (2002). The New Basics Education and the Future of Work in the Telematic Age. Association for Supervision and Curriculum Development: Alexandria, Virginia

Vasileiadou, M. (2009), Cooperative learning and its effects on pre-primary, marginalized children

Zambrano, J., Kirschner, F., Sweller, J. and Kirschner, P. (2019), Effects of group experience and information distribution on collaborative learning, Instructional Science volume 47, 531-550(2019) 